\title{
O PROCESSO DE NEGOCIAÇÃO E O ALCANCE DA COMPLETUDE MONOLÓGICA EM DEBATE ELEITORAL
}

\author{
NEGOTIATION PROCESS AND THE ATTAINMENT OF MONOLOGICAL \\ COMPLETENESS IN ELECTORAL DEBATE
}

\author{
Gustavo Ximenes Cunha*
}

\begin{abstract}
RESUMO
Neste trabalho, estudam-se as restrições impostas por uma propriedade contextual do gênero debate eleitoral (a saber, a reciprocidade parcial e controlada entre os interlocutores) sobre a tarefa dos candidatos de produzirem intervenções que possam ser avaliadas como completas. Adotando como arcabouço teórico a abordagem genebrina de análise do discurso (ou Escola de Genebra) e analisando o último debate eleitoral da campanha presidencial de 2014, debate cujos adversários foram Dilma Rousseff (PT) e Aécio Neves (PSDB), obtivemos os seguintes resultados: i) ao elaborarem perguntas, os candidatos as antecipam por uma intervenção preparatória funcional e estruturalmente complexa; ii) os candidatos elaboram as intervenções reativas (respostas, réplicas e tréplicas) por etapas que se ligam a informações oriundas da intervenção previamente produzida pelo adversário e/ou por integrante da plateia (eleitor) convidado a perguntar; iii) na construção de cada intervenção reativa, os candidatos podem ou coordenar essas mesmas etapas, ou as articular por subordinação; iv) em cada uma dessas etapas, os candidatos empregam segmentos de discurso que representam tanto a fala do adversário, quanto a fala do integrante da plateia convidado a perguntar.

Palavras-chave: processo de negociação; completude monológica; debate eleitoral.
\end{abstract}

\section{ABSTRACT}

In this paper, the objective is to study the constraints imposed by a contextual property of the electoral debate (namely, the partial and controlled reciprocity between the interlocutors) about the task of producing interventions that can be evaluated as complete. Adopting the Geneva Model of discourse analysis as theoretical framework and analyzing the last electoral debate of the presidential campaign that took place in 2014, a debate whose opponents were Dilma Rousseff (PT) and Aécio Neves (PSDB), we obtained the following results: i) in the intervention in which the candidates ask the question, it is anticipated by a functionally and structurally complex preparatory intervention; ii) reactive interventions (responses and replies) are formed by steps that are linked to information from the intervention previously produced by the opponent and/or audience member (voter) invited to ask; iii) in the construction of each reactive intervention, these steps can be coordinated or articulated by subordination; iv) in each of these steps, there may be discourse segments representing both the speech of the opponent and the speech of the audience member invited to ask.

Keywords: negotiation process; monological completion; election debate.

\section{INTRODUÇÃO}

Um dos objetivos da abordagem genebrina de análise do discurso (ou Escola de Genebra) é, mais do que simplesmente descrever como os interactantes participam de uma interação, explicar quais são as restrições contextuais que pesam sobre essa participação, impondo limitações sobre seu modo de agir ou sobre sua linha de conduta, e, consequentemente, quais são as relações entre essas restrições e a organização do discurso. A fim de alcançar essa explicação, elaboraram-se, no âmbito dessa abordagem, proposições acerca das regras e condições de encadeamento das intervenções constitutivas das trocas (MOESCHLER, 1982, 1985), da influência da situação de comunicação sobre a elaboração/estruturação de trocas e intervenções (ROULET, 1988, 2004, GROBET, 2012), da articulação das ações verbais e não verbais em ambientes institucionais (comerciais, industriais, escolares) (FILLIETTAZ; ROULET, 2002, FILLIETTAZ, 2004, 2006, 2008) etc.

Nesses estudos, as noções de negociação e de completude (dialógica e monológica) desempenham um papel central. Para Roulet $(1986,1987,2000$, ROULET et al, 1985), as pesquisas conduzidas no âmbito da Análise da Conversa acerca de fenômenos tais como interrupções, reformulações, correções e alternância de turnos de fala ${ }^{1}$ confirmam a hipótese de Bakhtin/Volochínov (1986[1929]) segundo a qual o discurso deve ser concebido como interação. Porém,

\footnotetext{
* Universidade Federal de Minas Gerais (UFMG), Belo Horizonte, MG, Brasil. ximenescunha@yahoo.com.br Orcid: https://orcid.org/0000-0001-9953-1204.

Agradeço ao CNPq a concessão da bolsa de Produtividade em Pesquisa (nível 2). Processo: 304244/2019-8.

1. O autor se refere ao estudo clássico de Sacks, Schegloff e Jefferson (1974), bem como a outros estudos da mesma corrente teórica produzidos nas décadas de 1970 e 1980.
} 
de acordo com Roulet, conceber o discurso como interação não permite apreender nem sua estrutura hierárquica, nem as restrições que determinam a construção dos constituintes textuais (ROULET et al, 1985). Por isso, propõe o autor ultrapassar a perspectiva interacional de Bakhtin e dos analistas da conversa, concebendo o discurso como negociação, ou seja, como um processo de ajustes sucessivos para o alcance das completudes monológica e dialógica (ROULET, 1986, 1987, 2000, ROULET et al, 1985).

$\mathrm{Na}$ acepção de Roulet (1986, 1987, 1999, ROULET et al, 1985), a noção de completude monológica corresponde às ações que o locutor realiza para produzir uma intervenção (cumprimento, pedido, recusa) que permita ao interlocutor reagir positiva ou negativamente a ela, ao passo que a noção de completude dialógica diz respeito às ações que os interlocutores realizam para alcançarem o entendimento de que a negociação chegou ao fim e pode ser encerrada. No que concerne à completude monológica, noção que será descrita de forma mais detalhada no próximo item, observa Roulet (ROULET et al, 1985) que, ainda que o locutor seja capaz de, ao elaborar sua intervenção, avaliar as expectativas de completude de seu interlocutor, é sempre este que, por meio de sua reação, revela se a intervenção do locutor foi de fato completa (adequada) para o desenvolvimento da interação. Tendo em vista essa dimensão fortemente dialógica, interpretativa e pragmática da noção de completude monológica (BURGER; JACQUIN, 2015), percebe-se que o contexto exerce papel relevante na avaliação dos interlocutores acerca do grau de in/completude das intervenções trocadas, já que do contexto fazem parte as representações dos interlocutores acerca de quem são um (uns) para o(s) outro(s) (FILLIETTAZ, 2006, 2014).

Embora a dimensão dialógica, interpretativa e pragmática da completude monológica seja um pressuposto dessa abordagem, explorou-se de forma pouco sistemática o impacto de diferentes contextos sobre o modo como os interlocutores buscam alcançar a completude monológica, ao longo da negociação. Em outros termos, explorouse pouco o fato de que a completude é um fenômeno não só dialógico, interpretativo e pragmático, mas ainda institucional, ou seja, ancorado em gêneros do discurso (BURGER; JACQUIN, 2015) ou nas práticas sociais e em suas formas típicas de agir por meio da linguagem (FILLIETTAZ, 2014).

Este trabalho, que aprofunda pesquisas por nós desenvolvidas sobre a relação entre contexto e processo de negociação (CUNHA, 2017, 2017a, 2017b, 2019; CUNHA; TOMAZI, 2019), estuda o impacto que uma propriedade contextual do gênero debate eleitoral - a reciprocidade parcial e controlada entre os adversários políticos - exerce sobre os adversários, levando-os a adotarem um modo de conduta específico para o alcance da completude de suas intervenções. Nosso objetivo é evidenciar, assim, que o fato de os candidatos não poderem decidir em que momento retroagir, intervindo quando a oportunidade surge, é a responsável pela realização de manobras bastante complexas para a realização de uma intervenção que possa ser avaliada como suficientemente completa pelo interlocutor, que, como veremos, pode ser tanto o adversário, quanto um eleitor convidado a perguntar.

Para alcançar esse objetivo, apresentaremos inicialmente a noção de completude, tal como formulada por Roulet (1986, 1987, 1999, 2000, ROULET et al, 1985, ROULET; FILLIETTAZ; GROBET, 2001). Nessa apresentação, verificaremos o impacto das restrições contextuais sobre a completude. Em seguida, descreveremos os passos metodológicos realizados ao longo da pesquisa. Nesse item, apresentaremos informações sobre a constituição e a análise do corpus (72 intervenções produzidas no último debate eleitoral da campanha presidencial de 2014, debate protagonizado por Dilma Rousseff (PT) e Aécio Neves (PSDB) e promovido pela Rede Globo). Por fim, no item de análise, exporemos os resultados alcançados acerca do modo como os candidatos agem, nesse debate, para tentar alcançar a completude monológica de suas intervenções.

\section{NEGOCIAÇÃO E COMPLETUDE MONOLÓGICA}

Na abordagem genebrina de análise do discurso, entende-se que, em todo encontro, os interactantes constroem uma intencionalidade compartilhada (enjeu) com base em suas intencionalidades individuais (ROULET, 1992; FILLIETTAZ, 2000, 2005). Conforme Roulet (1992, p. 94), "essa intencionalidade compartilhada é um constante objeto de negociação entre os interlocutores". Por exemplo, numa transação de compra e venda, gênero de interação extensamente estudado nessa abordagem (FILLIETTAZ, 2000, 2008; FILLIETTAZ; ROULET, 2002; ROULET; FILLIETTAZ; GROBET, 2001), a intencionalidade compartilhada (mercadejar bens de consumo) se constrói a partir de intencionalidades individuais: enquanto o vendedor quer vender produtos, o cliente quer comprá-los. $\mathrm{O}$ discurso é entendido, portanto, como todo o processo de negociação envolvendo a construção conjunta de uma 
intencionalidade compartilhada, processo que implica da parte de cada interactante a realização de manobras diversas ou de ajustes sucessivos. Esses ajustes estão ligados tanto à gestão global do encontro (como iniciá-lo, desenvolvêlo, encerrá-lo), quanto à gestão de cada uma de suas fases (como re/fazer ou recusar um convite, como re/elaborar um pedido ou uma demanda de informação, como apontar e ajudar a sanar problemas - incoerências, ambiguidades, obscuridades - na fala do interlocutor).

A completude (dialógica e monológica) é o conceito com que Roulet busca dar conta desses dois tipos de ajustes (ROULET et al, 1985, 1986, 1987; ROULET; FILLIETTAZ; GROBET, 2001). Propõe o autor que qualquer negociação consiste na realização de, pelo menos, três fases: o locutor realiza uma proposição, o interlocutor reage a essa proposição e o locutor ratifica a reação. Ressaltando a influência de Goffman (1973) no entendimento do discurso enquanto negociação, Filliettaz (2005) observa que, como as condutas verbais implicadas na realização de trocas reparadoras sempre colocam em perigo as faces em jogo ${ }^{2}$, a negociação, nessas trocas, compreende uma ofensa virtual inicial (proposição), em seguida sua reparação (reação) e, por fim, a ratificação dessa reparação. Com a ratificação, os interlocutores alcançam o duplo acordo, ou seja, chegam conjuntamente a um acordo quanto à possibilidade de finalizar a interação. A completude dialógica diz respeito à satisfação da restrição do duplo acordo, autorizando o encerramento da negociação, e está ligada, portanto, à gestão global do encontro.

Porém, para os interlocutores alcançarem o duplo acordo, cada fase da negociação (proposição, reação, ratificação) precisa ser elaborada de forma suficientemente completa, permitindo ao outro reagir de modo positivo ou negativo, apresentar uma contra-proposição, em caso de reação negativa, ou ratificar. Mais especificamente, o desenvolvimento da negociação exige que cada etapa, para poder ser considerada suficientemente completa, satisfaça dois tipos de exigências, sendo um de natureza comunicativa e o outro de natureza ritual (GOFFMAN, 1981; ROULET et al, 1985). Do ponto de vista comunicativo, cada etapa deve ser suficientemente informativa, não violando expectativas implícitas de clareza e pertinência, tais como as propostas por Grice (1975) por meio de suas máximas ou por Ducrot (1987) por meio de suas leis de discurso. Ao mesmo tempo, deve ser suficientemente adequada do ponto de vista ritual, não colocando em risco as faces e os territórios em jogo (GOFFMAN, 1967[1955], 1973). A observância dessas exigências comunicativas e rituais, quando da elaboração de cada fase do processo de negociação, corresponde à completude monológica.

Como ressalta Roulet, ainda que o locutor se esforce para construir uma intervenção que satisfaça a restrição de completude monológica, baseando-se na situação e no que sabe ou presume saber acerca do interlocutor, é sempre a este que cabe a tarefa de avaliar a in/completude da intervenção: "Só este [o interlocutor] pode julgar se a intervenção do locutor the fornece todos os elementos necessários para que possa tomar posição, exprimir seu acordo ou seu desacordo" (ROULET et al, 1985, p. 17). Dessa forma, se o interlocutor avalia que a intervenção não satisfaz a restrição de completude monológica, por não ser suficientemente clara ou justificada, ele, se o contexto o permite, é levado a suspender a negociação principal e iniciar uma negociação secundária, por meio da qual colabora com o locutor na construção de uma intervenção adequada para o desenvolvimento da negociação (ROULET et al, 1985; ROULET; FILLIETTAZ; GROBET, 2001; CUNHA, 2019; CUNHA, 2020; TOMAZI, 2019).

Neste trabalho, dedicamo-nos ao estudo da completude monológica em um debate eleitoral televisivo, por entendermos que as expectativas que tipicamente estruturam esse gênero do discurso impactam as manobras realizadas pelos interactantes para alcançarem a completude monológica (ROULET, 1988; JACQUIN, 2014; BURGER, JACQUIN, 2015; CUNHA, 2017b). Uma dessas expectativas é a existência ou não de reciprocidade entre os interactantes, que, como demonstrado em Cunha (2017), influencia diretamente as manobras que eles podem ou não realizar para o alcance da completude de cada fase do processo de negociação.

O debate eleitoral, tal como produzido pelas principais emissoras de televisão no Brasil, se caracteriza por uma reciprocidade controlada, parcial e não imediata. Isso significa que há regras explícitas e previamente acordadas entre os interactantes e o veículo de comunicação sobre as condições para a reciprocidade. Assim, diferentemente do que ocorre em uma conversa, que se caracteriza pela reciprocidade imediata, o que guia a decisão de um candidato por tomar a palavra não é a percepção de um lugar relevante para a transição (SACKS; SCHEGLOFF; JEFFERSON, 1974; SCHEGLOFF, 2007; JACQUIN, 2014) ou da completude da intervenção produzida pelo adversário (ROULET,

2. Para Goffman (1973), os encontros sociais se caracterizam por dois tipos de trocas rituais: as confirmativas e as reparadoras. As confirmativas são aquelas com que o locutor "presta homenagem" à face que o interlocutor reivindica na interação. Exemplo típico são as trocas de cumprimentos e despedidas. Já as reparadoras são as trocas com que o locutor busca reparar uma ofensa causada à face do interlocutor. 
2000; ROULET; FILLIETTAZ; GROBET, 2001). São antes regras que determinam a ordem em que os candidatos podem falar, bem como de quanto tempo cada um dispõe para elaborar a pergunta, a resposta, a réplica e a tréplica.

Como propriedade ritual dos debates, essas regras costumam ser explicitadas pelo moderador logo no início do encontro. Por exemplo, no início do primeiro bloco do debate por nós estudado, o moderador produziu uma intervenção em que apresentou as "regras do jogo". Nessa intervenção, ele informou a dinâmica de cada bloco do debate, esclarecendo: i) os blocos em que integrantes da plateia fariam perguntas, ii) o tempo máximo de produção das intervenções ("meio minuto para pergunta/. um minuto e meio para resposta/. cinquenta segundos para a réplica/. e cinquenta segundos para a tréplica \"), iii) regras rituais ou de polidez ("aquele que se sentir ofendido pessoalmente ou caluniado numa tréplica/ poderá pedir o direito de resposta/. e ele será analisado\\"), iv) a natureza da transmissão do debate ("esse debate está sendo transmitido na internet/ pelo G1") e v) o controle do tempo de fala ("todos os tempos serão cronometrados/ como temos feito habitualmente aquil $\backslash$ "). Esse conjunto de regras evidencia a grande diferença existente entre um debate eleitoral e uma conversa, no que se refere ao modo como os interlocutores podem desenvolver o processo de negociação. Afinal, essas regras revelam que uma característica central do debate é, ao contrário do que costuma ocorrer em conversas, o controle "externo" ou institucional da linha de conduta dos interlocutores, de que faz parte a ausência de reciprocidade imediata.

Como exposto, essa propriedade situacional (ou contextual) do debate eleitoral brasileiro tem impacto sobre as manobras que os candidatos podem realizar para alcançar a completude monológica, na busca por elaborar uma intervenção que seja considerada pelo outro (adversário, mas também eleitores) suficientemente adequada. Nesse gênero de debate, as intervenções que cada candidato produz exibem uma complexidade elevada (CUNHA, 2017b) em decorrência do fato de que cada intervenção costuma ser composta por respostas a perguntas, refutações de críticas, críticas ao adversário e a terceiros, promessas de realização de ações futuras, exposição de pontos do programa de governo etc. Com isso, um candidato é obrigado a "deixar passar" os lugares relevantes para a transição que identifica na fala do adversário e aguardar sua vez de falar, para só então elaborar uma reação ou uma contra-proposição que se materializará em intervenção estruturalmente complexa, porque formada por constituintes (atos, intervenções e mesmo trocas) cuja função é responder (criticar, contra-argumentar, refutar) à intervenção previamente produzida. É essa complexidade envolvida no alcance da completude monológica que buscaremos descrever no item de análise deste trabalho, logo após apresentarmos os procedimentos de análise adotados na condução da pesquisa.

\section{PROCEDIMENTOS DE OBTENÇÃO E ANÁLISE DO CORPUS}

Neste trabalho, a apresentação de procedimentos de obtenção e análise do corpus se faz necessária, já que, tendo em vista nosso objetivo de estudar o modo como os candidatos buscam alcançar a completude monológica, nosso corpus se constitui não de um debate completo ou do total das intervenções nele produzidas por adversários, moderador e integrantes da plateia, mas por um subconjunto dessas intervenções ou das 72 perguntas, respostas, réplicas e tréplicas elaboradas pelos candidatos. Neste item, nosso intuito é, portanto, explicitar os procedimentos tomados para que chegássemos a esse corpus.

A primeira etapa do estudo consistiu no acesso ao debate e em sua transcrição. Como exposto na Introdução, analisamos o último debate eleitoral da campanha presidencial de 2014, debate protagonizado por Dilma Rousseff (PT), então Presidenta da República e candidata à reeleição, e Aécio Neves (PSDB), candidato da oposição, e promovido pela Rede Globo. Dada a impossibilidade de coleta do debate in loco, baseamo-nos na filmagem disponível no site do veículo de comunicação que o promoveu ${ }^{3}$. Embora a filmagem não tenha sido realizada para fins de pesquisa, ela constitui um documento válido para uma pesquisa que, como a nossa, focaliza a construção das intervenções dos candidatos, não levando em conta, por exemplo, as ações não verbais que realizaram ao longo da negociação, ações apenas parcialmente captadas na filmagem. Além disso, os procedimentos de encenação próprios do debate não invalidam o uso da filmagem em uma pesquisa que, como a nossa, se insere no campo dos estudos do discurso, uma vez que o impacto desses procedimentos sobre o comportamento linguageiro e não-linguageiro dos candidatos constitui parte inalienável do fenômeno que procuramos investigar (JACQUIN, 2014).

A etapa seguinte consistiu na transcrição do debate e em sua segmentação em atos, sendo o ato a unidade mínima de análise adotada na abordagem genebrina (ROULET; FILLIETTAZ; GROBET, 2001). A transcrição que

3. <http://g1.globo.com/politica/eleicoes/2014/transcricao-debate-presidencial-2-turno.html> 
realizamos tomou como ponto de partida a que está disponível no site onde coletamos a filmagem. No entanto, na busca por uma transcrição que correspondesse ao processo de negociação efetivamente desenvolvido pelos adversários, a transcrição disponível no site foi refeita a partir da audição do debate completo e com a utilização das convenções de transcrição adotadas em grande parte dos trabalhos da Escola de Genebra ${ }^{4}$. Quanto à segmentação do debate em atos, ela envolveu a aplicação de critérios de ordem, sobretudo, sintática, prosódica e hierárquica 5 . A numeração constante dos excertos analisados ao longo deste estudo é resultante desse trabalho de segmentação.

Como terceira etapa do estudo, foi necessário realizar uma análise macrotextual do debate. Essa análise correspondeu à identificação das trocas que materializam os vários processos de negociação de que o debate se compõe. Como resultado dessa etapa, verificamos que o debate constitui uma unidade acional bastante complexa, por ser formada por unidades acionais de menor proporção. Assim, o debate completo constitui um encontro (uma incursão) formado por quatro grandes blocos. Cada bloco, por sua vez, se constitui de transações (seis no $1^{\circ}$ e no $3^{\circ}$ blocos, quatro no $2^{\circ}$ e no $4^{\circ}$ blocos), cada uma das quais formada invariavelmente de pergunta, resposta, réplica e tréplica ${ }^{6}$.

No plano textual, cada transação corresponde a uma troca ou a um processo de negociação independente dos demais. Nos $1^{\circ}$ e $3^{\circ}$ blocos, em que a pergunta é realizada por um dos candidatos, a troca é formada por proposição (pergunta), reação negativa (resposta), contra-proposição (réplica), nova reação negativa (tréplica). Nos $4^{\circ}$ e $6^{\circ}$ blocos, em que a pergunta é realizada por um integrante da plateia, a troca é formada por proposição (pergunta), reação positiva (resposta de um candidato), reação negativa (réplica do outro candidato), nova reação negativa (tréplica do primeiro candidato). Todas as trocas apresentaram uma estrutura linear, ou seja, sem negociações secundárias interrompendo a negociação principal, sendo as intervenções de que se compõem articuladas por relações ilocucionárias de pergunta, asserção e resposta ${ }^{7}$.

No debate estudado, nenhuma das trocas apresentou a fase de ratificação. Essa ausência evidenciou que os adversários não alcançaram a completude dialógica (ou o duplo acordo) em nenhuma das negociações, o que é próprio de interações agonais ou que envolvem conflito e disputa (CUNHA, 2019). Por isso, ao final de cada troca, isto é, após cada tréplica, o mediador interveio, pondo fim à negociação. Na parte final de todo o debate, cada candidato produziu uma derradeira intervenção em que, dirigindo-se ao eleitorado, reforçou promessas e intenções de campanha e solicitou o voto.

Nessa terceira etapa do estudo, foi possível identificar o total de perguntas, respostas, réplicas e tréplicas que cada candidato elaborou. Como nos $2^{\circ}$ e $4^{\circ}$ blocos do debate as perguntas foram realizadas exclusivamente por integrantes da plateia, identificamos ainda o número dessas perguntas. A tabela 1 apresenta os resultados dessa análise.

4. Convenções de transcrição: / - \(contorno melódico continuativo ascendente, plano ou descendente), // = $\backslash \backslash$ (contorno melódico conclusivo ascendente, plano ou descendente), ... (pausa mais ou menos longa), : :: (alongamento mais ou menos acentuado), sublinhado (recobrimento de fala), [ ] comentário, risos, mudança de elocução ou de amplitude, ( ) palavra cuja compreensão é incerta, (X) sílaba incompreensível (ROULET; FILLIETTAZ; GROBET, 2001, p. 407).

5. Conforme Roulet (1999, p. 145), o ato é "a menor unidade delimitada de uma parte a outra por uma passagem pela memória discursiva". A memória discursiva, na acepção de Berrendonner (1983, p. 230), corresponde ao "conjunto de saberes conscientemente partilhados pelos interlocutores". Dois conjuntos de critérios auxiliam a identificar a passagem pela memória discursiva (ROSSARI, 1996, p. 162-163): a) critérios relativos ao reconhecimento das unidades da macrossintaxe que sinalizam uma mudança de estado da memória discursiva (ou uma passagem pela memória discursiva), tais como a presença de conectores e marcadores conversacionais sinalizando a fronteira entre atos e a possibilidade de usar indiferentemente um pronome ou uma expressão nominal definida para marcar a correferência; b) critérios relativos às indicações deixadas pelo tratamento periódico da cadeia discursiva (indicações suprassegmentais (prosódia) ou gráficas (pontuação). Apresentações mais detalhadas desses critérios encontram-se em Grobet (2000), Marinho (2007) e Roulet, Filliettaz e Grobet (2001, cap. 3).

6. A transação é a unidade acional formada pelas condutas ligadas a um foco central ou "objeto transacional" (FILLIETTAZ, 2000; ROULET; FILLIETTAZ; GROBET, 2001). Em um debate eleitoral, a transação corresponde ao conjunto das condutas ligadas à discussão de cada tópico (educação, saúde, trabalho, mobilidade urbana).

7. Roulet propõe dois tipos de relações de discurso: as ilocucionárias, cujo estabelecimento está ligado à restrição de completude dialógica, e as interativas, cujo estabelecimento está ligado à restrição de completude monológica. Para cada um dos tipos, o autor propõe categorias genéricas de relações. As categorias de relações ilocucionárias são: iniciativas (pergunta, pedido e asserção) e reativas (resposta e ratificação). Já as categorias de relações interativas são: argumento, contra-argumento, reformulação, topicalização, sucessão, preparação, comentário, clarificação (ROULET; FILLIETTAZ; GROBET, 2001). 
Tabela 1. total de intervenções no debate

\begin{tabular}{|l|c|c|c|c|c|}
\hline Locutores & Perguntas & Respostas & Réplicas & Tréplicas & Totais \\
\hline Aécio Neves & 6 & 10 & 10 & 10 & 36 \\
\hline Dilma Rousseff & 6 & 10 & 10 & 10 & 36 \\
\hline Eleitores & 8 & - & - & - & 8 \\
\hline Totais & 20 & 20 & 20 & 20 & 80 \\
\hline
\end{tabular}

Porque nosso intuito é estudar as intervenções produzidas por candidatos, as oito perguntas elaboradas por integrantes da plateia não foram analisadas. Sendo assim, a análise do modo como os candidatos buscaram alcançar a completude monológica no debate selecionado focalizou as 72 intervenções de pergunta, resposta, réplica e tréplica produzidas por Dilma Rousseff e Aécio Neves. Os resultados dessa análise e sua discussão serão apresentados no item a seguir.

\section{A COMPLETUDE MONOLÓGICA EM UM DEBATE ELEITORAL PRESIDENCIAL}

Como exposto, o modo como cada candidato busca alcançar a completude monológica, produzindo intervenções que possam ser avaliadas pelo outro (adversário e eleitores) como suficientemente completas, é fortemente impactado pela ausência de reciprocidade imediata, ou melhor, pela reciprocidade controlada pela emissora que promove o debate (CUNHA, 2017). Neste item, evidencia-se como esse impacto ocorre no debate protagonizado por Dilma Rousseff e Aécio Neves (doravante DR e AN, respectivamente). Iniciaremos a apresentação e a discussão das análises pelas perguntas elaboradas pelos candidatos. Em seguida, abordaremos conjuntamente as demais intervenções (respostas, réplicas, tréplicas), mas chamando a atenção para as diferenças detectadas entre as trocas iniciadas por candidatos e as trocas iniciadas por eleitores, quanto ao modo de alcance da completude monológica nessas intervenções.

Ao elaborar as perguntas, cada candidato precisou utilizar o tempo predeterminado de trinta segundos para produzir uma intervenção que pudesse ser considerada completa ou adequada tanto do ponto de vista comunicativo, quanto do ponto de vista ritual por adversário e eleitores. Para elaborar essa fase inicial da negociação, os dois candidatos adotaram a mesma estratégia de alcance da completude monológica. Eles as iniciaram com uma asserção e a finalizaram com a pergunta. Como decorrência da natureza polilogal do debate (KERBRAT-ORECCHIONI, $2017)^{8}$, a asserção se mostrou funcionalmente complexa, por se caracterizar por alguns valores ilocucionários. Com essa asserção, cada candidato, ao mesmo tempo, criticou o adversário, autoelogiou-se e alertou o eleitor acerca dos problemas que a vitória do adversário poderia acarretar. Quanto à pergunta, ela não constituiu uma demanda genuína de informação ou de confirmação em nenhuma das doze ocorrências, já que, tal como revelado por KerbratOrecchioni (2017), em debates não há um real interesse do candidato que a elabora em conhecer as propostas do adversário. Essa pergunta constituiu antes um recurso para colocar o adversário numa situação embaraçosa diante do eleitorado, como exemplifica o excerto 1.

1) DILMA ROUSSEFF: (1) candidato/ eu sempre gosto de perguntar a respeito do pronatec\. (2) por que que eu gosto do pronatec/ candidato//. (3) porque o pronatec/ (4) ele resolve várias questões e desafios \\. (5) vocês fizeram uma lei/ proibindo que o governo federal fizesse e mantivesse escolas técnicas $\backslash$. (6) por isso fizeram ao longo de oito anos/ só onze escolas técnicas \\. (7) o senhor era líder do governo FHC/. (8) o senhor vai continuar com essa política//

Na tarefa de elaborar uma proposição suficientemente completa, DR a inicia anunciando o tópico da pergunta: "(1) candidato/ eu sempre gosto de perguntar a respeito do pronatecl.". Num contexto de reciprocidade imediata, o adversário, baseando-se em propriedades sintáticas e prosódicas do ato (1), poderia identificar um lugar relevante para a transição após "pronatec" e questionar: "Por que você gosta de perguntar a respeito do Pronatec?". Uma objeção como essa não sendo possível no debate, dado o controle da reciprocidade que o caracteriza, a própria

8. Em função do dialogismo inerente à linguagem, o discurso é sempre dialógico e nunca monológico (BAKHTIN/VOLOCHÍNOV, 1986[1929]). Mas, no que se refere à sua realização material, ele pode ser monologal, se produzido por um locutor, dialogal, se produzido por dois, ou polilogal, se produzido por muitos (ROULET; FILLIETTAZ; GROBET, 2001; KERBRAT-ORECCHIONI, 2017). 
candidata se antecipa e produz uma troca subordinada com função de clarificação: "(2) por que que eu gosto do pronatec/ candidato//. (3) porque o pronatec/ (4) ele resolve várias questões e desafios \\.". Nesse debate, a menção às qualidades do Pronatec funciona como um autoelogio, na medida em que se refere a ações do governo da candidata, que, enquanto Presidenta da República, disputava a reeleição. As qualidades do programa, expressas em (1-4), poderiam constituir uma preparação para a pergunta feita em (8): "o senhor vai continuar com essa política// [com o Pronatec]". Com essa configuração, o adversário teria uma proposição suficientemente completa, a partir da qual poderia responder.

Porém, como DR dialoga não só com o adversário, mas também com os eleitores, uma intervenção suficientemente completa, no contexto de um debate eleitoral, precisa ainda constituir um alerta sobre o perigo que a vitória do adversário representa. Por isso, DR subordina retroativamente a intervenção (1-4) à intervenção formada pelos atos (5-7), em que menciona a lei criada pela oposição ("vocês", "governo FHC") que proíbe escolas técnicas, construindo uma asserção (1-7) estruturalmente complexa. A demanda de confirmação feita em (08) recai exatamente sobre a conclusão derivada da intervenção (05-07): Se vocês fizeram uma lei proibindo escolas técnicas, conclui-se que você, se eleito, não vai continuar com o Pronatec. Por isso, como exposto, raramente as perguntas em debates constituem verdadeiras demandas de informação ou de confirmação.

Ainda que cada uma das doze perguntas feitas pelos candidatos nos $1^{\circ}$ e $3^{\circ}$ blocos do debate tenha uma configuração estrutural particular, em todas elas os candidatos seguiram uma linha de conduta semelhante em sua tarefa de tentar alcançar a completude monológica, linha de conduta exemplificada com o excerto 1: elaboraram uma asserção funcional e estruturalmente complexa como preparação para a pergunta.

Na sequência deste item, abordaremos os resultados da análise das demais intervenções (respostas, réplicas e tréplicas) produzidas pelos candidatos. A análise não identificou especificidades na elaboração de cada uma dessas fases do processo de negociação. Em outros termos, diferentemente da pergunta, em cuja composição os candidatos adotaram uma linha de conduta específica para essa fase de abertura da negociação, as manobras realizadas por eles para o alcance da completude em respostas, réplicas e tréplicas foram as mesmas, não sendo possível diferenciar cada uma dessas fases em relação às outras. Entretanto, identificamos diferenças de estratégias para o alcance da completude entre as intervenções componentes das trocas iniciadas pelos próprios candidatos $\left(1^{\circ}\right.$ e $3^{\circ}$ blocos do debate) e as intervenções componentes das trocas iniciadas por integrantes da plateia ( $2^{\circ}$ e $4^{\circ}$ blocos do debate). Assim, no que se refere ao modo como os candidatos buscam alcançar a completude monológica num contexto que proíbe a reciprocidade imediata, os fenômenos mais recorrentemente identificados na análise foram estes:

a) cada intervenção (resposta, réplica ou tréplica) costuma ser constituída de etapas correspondentes a intervenções de extensão e complexidade variadas. Nas trocas iniciadas por candidatos, cada uma dessas etapas se liga a uma informação da memória discursiva (doravante $\mathrm{MD}$ ) ${ }^{9}$ com origem na intervenção previamente produzida pelo adversário; já nas trocas iniciadas por integrantes da plateia, cada uma dessas etapas se liga a uma informação da MD com origem em intervenções previamente produzidas pelo adversário e/ou na pergunta inicialmente feita pelo integrante da plateia;

b) nas trocas iniciadas por candidatos, cada intervenção (resposta, réplica ou tréplica) costuma ser elaborada por coordenação de intervenções (correspondentes às etapas mencionadas em a); já nas trocas iniciadas por integrantes da plateia, cada intervenção costuma ser elaborada por subordinação de intervenções (também correspondentes às etapas mencionadas em $a)_{\text {; }}$

c) nas intervenções das trocas iniciadas por candidatos, são recorrentes segmentos de discurso representando a fala do adversário ( $2^{a}$ pessoa); já nas intervenções das trocas iniciadas por integrantes da plateia, são recorrentes segmentos de discurso representando a fala do integrante da plateia ( $2^{\text {a }}$ pessoa) e de segmentos de discurso representando a fala do adversário ( $3^{\mathrm{a}}$ pessoa).

Para maior clareza em nossa exposição, a seguir abordaremos separadamente cada um desses fenômenos.

9. Como informado na nota 5, a memória discursiva corresponde ao "conjunto de saberes conscientemente partilhados pelos interlocutores" (BERRENDONNER, 1983, p. 230). Ela compreende "os diversos pré-requisitos culturais (normas comunicativas, lugares argumentativos, saberes enciclopédicos comuns etc.) que servem de axiomas aos interlocutores para conduzir uma atividade dedutiva", bem como "as enunciações sucessivas que constituem o discurso" (ROULET; FILLIETTAZ; GROBET, 2001, p. 23). 


\subsection{Construção de intervenções por etapas}

Ao elaborar uma intervenção reativa (resposta, réplica ou tréplica), cada candidato realizou sucessivamente várias ações, tais como refutar uma afirmação feita previamente pelo adversário, negar a pertinência de suas propostas, apontar o desconhecimento do adversário acerca de programas e da agenda governamental ou de problemas vividos por segmentos da população, questionar sua legitimidade para abordar determinado tópico ou ainda elogiar a pergunta de integrante da plateia. Dessa forma, a tentativa de cada candidato de alcançar a completude monológica se deu por etapas, cada uma das quais lhe permitindo responder (criticar, refutar, comentar) uma informação ou informações pertencentes ao conjunto do que foi dito pelo adversário ou por integrante da plateia.

Cada etapa de construção das intervenções exibiu uma completude parcial, já que apresentou propriedades textuais, informacionais e prosódicas próprias de uma fase do processo de negociação. Assim, se o debate se caracterizasse pela reciprocidade imediata, cada uma dessas etapas poderia constituir um turno de fala, uma vez que as propriedades mencionadas compõem um feixe de traços que sinaliza para o interlocutor que o fim da etapa corresponde a um lugar relevante para a transição. Especifiquemos melhor essas propriedades e seu papel na sinalização da completude de cada etapa.

Do ponto de vista textual, cada etapa de construção da resposta, da réplica e da tréplica constitui uma intervenção complexa, ou seja, um constituinte textual formado por um ato que dá a orientação ilocucionária (crítica, refutação, elogio etc.) da etapa, ato em relação ao qual o locutor, em função da necessidade de atender às restrições comunicativas e rituais da completude monológica, subordina atos, intervenções e mesmo trocas que justificam, preparam, explicam, clarificam, comentam ou exemplificam esse ato. Ainda do ponto de vista textual, cada etapa se liga a uma informação previamente estocada na MD cuja origem é a fala do adversário ou de integrante da plateia. Por meio dessa articulação, o candidato subordina a fala do outro à sua, para trazer, em relação a essa fala, um contraargumento, um elogio, um argumento conclusivo, uma reformulação, atualizando esquemas como: você disse $x$, mas a verdade é que $y$; você disse $x$, portanto deve admitir que $y$; você disse $x$, ou seja, você disse $y$.

Do ponto de vista informacional, ao ligar a etapa que produz a uma informação da MD previamente expressa pelo outro, o candidato faz de toda essa informação ou de parte dela o tópico da etapa ${ }^{10}$. Com isso, cada etapa de elaboração de dada intervenção retira sua unidade tópica de um processo de ancoragem que a encadeia a um tópico, que é uma informação da MD com origem na fala do interlocutor. Assim, garante-se a continuidade informacional entre a etapa produzida pelo candidato e o que este presume que o interlocutor disse.

A completude parcial de cada etapa de construção das intervenções de resposta, réplica e tréplica é atestada ainda pela prosódia. Cada etapa corresponde a, pelo menos, um movimento periódico, ou seja, a um constituinte textual caracterizado por entoação descendente (construção declarativa) ou ascendente (construção interrogativa) e conclusiva (ROULET, 1999; GROBET, 2000; ROULET; FILLIETTAZ; GROBET, 2001).

Vejamos como essas propriedades textuais, informacionais e prosódicas se manifestam na intervenção (réplica) produzida por DR no excerto 2.

2) AÉCIO NEVES: (...) (6) temos uma taxa de investimentos hoje de dezesseis e meio por cento do PIB/. (7) a pior da década $\backslash$ (8) porque o seu governo afugentou os investimentos $\backslash$ (9) e a inflação infelizmente está de volta \\. (...) (28) a senhora será a primeira presidente da república pós plano real/ que deixará o país com uma inflação maior do que aquela que recebeu \\

DILMA ROUSSEFF: (1) eu acho que o senhor está mal informado\. (2) porque quem deixou o país com uma inflação maior do que recebeu/ foi o governo tucano do Fernando Henriquell. (3) além disso candidato/ eu queria dizer que nós criamos empregos $\operatorname{sim} \backslash$ candidato $\backslash \backslash$ (4) e o senhor não pode questionar esse fato $\backslash$. (5) são dados reais \\. (6) nós aumentamos o salário mínimo/. setenta e um por cento em termos reais \. (7) além disso candidato/ na saúde/ quem não gastou o mínimo constitucional foi o senhor (8) quando era governador $\backslash$ (9) que ficou devendo oito bilhões \. (10) além disso candidato/ eu quero deixar claro que eu tenho certeza que eu neste próximo mandato/ farei um governo muito melhor/ (11) se for eleita \(12) principalmente controlando a inflação\\

10. Na abordagem genebrina de análise do discurso, o tópico é definido como "uma informação identificável e presente na consciência dos interlocutores, que constitui, para cada ato, o ponto de ancoragem mais imediatamente pertinente, mantendo uma relação de 'a propósito' (aboutness) com a informação ativada por esse ato" (ROULET; FILLIETTAZ; GROBET, 2001, p. 255). 
Para tentar alcançar a completude monológica de sua réplica, DR a constrói em quatro etapas. Por motivo de espaço, analisaremos de forma detida apenas a primeira, que corresponde à intervenção formada pelos atos (1-2).

Do ponto de vista textual, o ato (1) ("eu acho que o senhor está mal informadol.") dá a orientação ilocucionária da intervenção (refutação), enquanto o ato (2) ("porque quem deixou o país com uma inflação maior do que recebeu/ foi o governo tucano do Fernando Henriquel\.") justifica a refutação. Assim formada, a intervenção (1-2) permite à candidata refutar esta asserção feita previamente pelo adversário: "(28) a senhora será a primeira presidente da república pós plano real/ que deixará o país com uma inflação maior do que aquela que recebeu \\". Por isso, a intervenção (1-2) de DR se liga à informação ativada em (28) por uma relação de contra-argumento, já que a candidata faz da fala do adversário o contra-argumento que refuta ao dizer: "(1) eu acho que o senhor está mal informado\. (2) porque quem deixou o país com uma inflação maior do que recebeu/ foi o governo tucano do Fernando Henriquell.".

Do ponto de vista informacional, DR produz uma intervenção cujo tópico é a informação inflação, ativada inicialmente no ato (9) da intervenção do adversário ("(9) e a inflação infelizmente está de voltall."). Desse modo, tanto DR quanto AN tratam de um mesmo tópico: inflação. Também a prosódia auxilia na identificação da primeira etapa de formulação da réplica de $\mathrm{DR}$, já que, assim como as demais, ela constitui um movimento periódico caracterizado pela entoação descendente e conclusiva, o que é sinalizado pela barra dupla e pelo ponto sinalizando uma pausa curta (\.).

Toda a réplica de DR é bastante representativa do que ocorre ao longo do debate. Em função das restrições que pesam sobre os candidatos, das quais a mais significativa, para este trabalho, é a ausência de reciprocidade imediata, a candidata precisa, em um minuto e trinta segundos, elaborar uma réplica que possa ser considerada completa não só pelo adversário, mas também pelos eleitores que colaboram igualmente no desenvolvimento do processo de negociação. Por isso, a candidata adota o procedimento de tentar alcançar a completude da réplica por etapas, cada uma das quais possuindo uma completude parcial e constituindo a refutação de asserção feita previamente pelo adversário.

No entanto, se a intervenção produzida por DR é representativa do que ocorre em todo o debate, esse modo de tentar alcançar a completude monológica sofreu alterações nas trocas iniciadas por perguntas de integrantes da plateia (eleitores). Nessas trocas, o candidato precisou construir respostas, réplicas e tréplicas formadas por intervenções que se ligaram não só a informações da fala do adversário, mas também à pergunta do eleitor, o que resultou em intervenções mais complexas, já que o alcance da completude monológica se tornou mais difícil, como se verifica no fragmento da réplica de AN presente no excerto 3.

3) LUIZ ALEXANDRE FILHO: (1) meu nome é Luiz Alexandre Filho/. (2) eu tenho quarenta e três anos \. (3) sou florista\\. (4) qual será/ qual será/ é:: (5) desculpel\. (6) qual será a sua política para quem mora de aluguel//. (7) pois está cada vez mais difícil e muito mais caro alugar uma casal. (8) os preços estão muito acima da inflação\. (9) moro há 15 anos/ (10) e o meu aluguel triplicou nos últimos quatro anos \\

DILMA ROUSSEFF: (...) (13) assim Luiz Alexandrel. nós vamos fazer/ (14) se eu for eleita/ (15) mais três milhões de casas do minha casa minha vida \} ( \ldots )

AÉCIO NEVES: (1) Luiz Alexandre/ esse é um drama que milhões de brasileiros vivem\. (2) a dificuldade de pagar aluguel/ (3) e a dificuldade de ter a sua casa próprial\. (4) ao contrário daquilo que nós assistimos na propaganda oficial/ (5) não foram entregues três milhões e meio de habitações no Brasil\\. (6) foram entregues metade dissol\. (7) se tivesse sido entregue esses três milhões e meio de habitações/. (8) provavelmente um milhão e meio ou um pouco mais disso de brasileiros estaria numa situação hoje de muito mais tranquilidade \l. (9) nós vamos ampliar esses programas habitacionais/ (10) com parcerias mais efetivas e desburocratizadas/ com os municípios e com os estados brasileiros $\backslash \backslash(\ldots)$

$\mathrm{O}$ fragmento da réplica de $\mathrm{AN}$ se constitui de três etapas. A primeira, que corresponde aos atos (1-3), se liga à justificativa do eleitor para a realização da pergunta ("(7) pois está cada vez mais difícil e muito mais caro alugar uma casa \. (8) os preços estão muito acima da inflação\.") e ao comentário que ele, nos atos (9-10), fez de toda a pergunta ("(9) moro há 15 anos/ (10) e o meu aluguel triplicou nos últimos quatro anos\\"). A segunda etapa da réplica do candidato corresponde aos atos (4-8) e se liga à proposta expressa nos atos (13-15) da resposta de DR. Por fim, a 
terceira etapa, que corresponde ao restante da intervenção de AN, se liga, respondendo, à pergunta do eleitor ("(6) qual será a sua política para quem mora de aluguel//.").

Esse exemplo evidencia bem a complexidade das manobras envolvidas no alcance da completude monológica em debate eleitoral. Tendo em vista as exigências comunicativas e rituais próprias desse tipo de completude, o candidato evidencia que, para ele, seu alcance não se restringe a responder à pergunta do eleitor (terceira etapa). É preciso ainda mostrar-se solidário em relação ao drama vivido por ele, valorizando a face do eleitor e a sua própria face (primeira etapa), e desacreditar as propostas da adversária, atacando sua face (segunda etapa). Em função da ausência de reciprocidade imediata, essas manobras devem ser realizadas não no momento em que a oportunidade surge, mas em ocasiões predeterminadas e em uma única intervenção.

\subsection{Elaboração das respostas, réplicas e tréplicas por coordenação ou por subordinação de intervenções (etapas)}

Neste subitem, interessa-nos abordar não o modo como cada etapa de construção das intervenções dos candidatos se liga a informações da MD com origem na fala de adversário ou eleitor, tarefa que realizamos no último subitem, mas sim a organização interna de cada resposta, réplica e tréplica, verificando o modo como as etapas identificadas no subitem anterior se articulam entre si. Nas trocas iniciadas por candidatos, verificamos que estes coordenaram as intervenções correspondentes a essas etapas. Já nas trocas iniciadas por integrantes da plateia, os candidatos articularam, sobretudo, por subordinação as intervenções correspondentes a essas etapas. Neste subitem, abordaremos, primeiro, as trocas iniciadas por candidatos e, em seguida, aquelas iniciadas por eleitores.

Porque, no debate, um candidato não pode interromper o adversário, ele precisa esperar sua vez de falar, ignorando, como já dito, os lugares relevantes para a transição que identifica na intervenção do adversário. Assim, quando toma a palavra, o candidato, na busca por elaborar uma intervenção completa (adequada), é levado a coordenar as intervenções correspondentes às etapas estudadas. É o que ocorre na resposta de DR no excerto 4.

4) AÉCIO NEVES: (1) candidata/ a diretora de assistência social do seu governo confirmou essa semana numa reunião com prefeitos em Minas Gerais/ que os repasses do fundo nacional de assistência estão atrasados em três meses \\. (2) esse fundo na verdade/ (3) ele atende aos programas mais fundamentais do seu governo\. (4) programas de assistência de repasse de recursos para entidades que prestam a primeira atenção às pessoas que mais necessitam \\. (5) em relação ao orçamento voltado às pessoas portadoras com deficiência/ (6) que é o termo adequado/ (7) foi executado apenas onze por cento do que foi aprovado até aquil\. (8) o que vem acontecendo com seu governo/ candidata//

DILMA ROUSSEFF: (1) candidato/ acho que o senhor está muito mal informado \\. (2) o meu governo tem feito um imenso esforço/ (3) para levar atendimento de saúde de educação e acessibilidade a pessoas com deficiência \. (...) (9) eu não tenho a menor dúvida em afirmar para o senhor/ e aqui para os nossos eleitores indecisos/ que o meu governo não atrasa programas sociais $\backslash \backslash$. (10) nunca atrasou nem contingenciou $\backslash$. (11) e quero dizer mais uma coisa para vocês $\backslash$. (12) enquanto vocês no bolsa família/ por todos os oito anos do governo Fernando Henrique/ gastaram quatro bilhões e duzentos/ (13) nós gastamos quatro bilhões e duzentos em apenas dois meses de pagamento do bolsa famílial\. (14) não tem a menor dimensão nem comparativa/ com o governo que vocês fizeram \\

A maior parte da resposta da candidata busca refutar a asserção (acusação) do adversário, segundo o qual, nos atos (1-4) de sua pergunta, os repasses do Fundo Nacional de Assistência estariam atrasados em três meses. Para isso, ela, nos atos (1-10), o acusa de estar mal informado e justifica a acusação, na tentativa de elaborar uma intervenção que possa ser avaliada como completa tanto do ponto de vista comunicativo (em debates, é preciso sustentar acusações com argumentos (MOESCHLER, 1982)), quanto do ponto de vista ritual (a justificativa ameniza o grau de agressividade da acusação para a face do acusado (BROWN; LEVINSON, 1983) e, em trocas agonais, como debates, permite ao acusador reparar sua própria face, defendendo-se (CUNHA, 2019)).

Mas, porque a intervenção que produz deve ser suficientemente completa não só para o adversário, mas também para os eleitores, DR finaliza sua resposta, produzindo a intervenção (11-14), com a qual questiona a legitimidade do adversário em fazer uma pergunta sobre investimento em programas assistenciais. Agindo dessa forma, a candidata 
tenta alcançar a completude de sua resposta, coordenando duas intervenções ou dois argumentos que levam a uma mesma conclusão implícita: Não bá problemas no men governo, mas bouve no de FHC.

O reflexo dessa estratégia de coordenar as etapas com as quais os candidatos reagem a diferentes informações da MD é a presença de atos preparatórios metadiscursivos, como "(11) e quero dizer mais uma coisa para vocês $\backslash \backslash$. ." presente na resposta de DR, e de conectores atuando como simples juntores dessas etapas e não como marcas de subordinação textual/hierárquica. No debate em análise, identificamos o uso de conectores como e, agora e além disso. Intervenção em que esse uso é bastante representativo é a réplica de DR já analisada anteriormente (excerto 2). Nela a expressão "além disso [candidato]" é usada pela candidata para indicar um acúmulo de argumentos, todos de mesma importância (GUIMARÃES, 1987), cada uma das três ocorrências da expressão sinalizando o fim de um argumento e o início de outro.

Já nas trocas iniciadas por integrantes da plateia, os candidatos, como exposto, costumam articular por subordinação as intervenções correspondentes às etapas de formulação de suas respostas, réplicas e tréplicas. O excerto 5, que se constitui da pergunta de uma eleitora, da resposta de DR e da réplica de AN, é um exemplo disso.

5) ADRIANA PEREIRA DOS SANTOS: (1) meu nome é Adriana Pereira dos Santos $\backslash$ (2) tenho quarenta anos/ (3) sou assistente de compras $\backslash$. (4) a corrupção é uma doença contagiosa/ que tem sido uma pedra no calcanhar de todos os governos $\backslash(5)$ causando danos irreparáveis $\backslash \backslash$. (6) acredito que isso se dá/ porque a lei que pune os corruptos é muito branda \. (7) candidata/ como pretende acabar com a corrupção no Brasil/ (8) e fazer com que os responsáveis sejam punidos de forma exemplar pelos seus atos/ (9) que tanto envergonham o nosso Brasil//

DILMA ROUSSEFF: (1) Adriana/ você tem toda a razão\. (2) a lei é branda\\. (3) quando a lei é branda/ (4) você investiga/. (5) você identifica/. (6) e na hora de punir o criminoso/ (7) o corrupto se evadel\. (8) por isso que eu propus cinco grandes medidas de combate à impunidade $\backslash$. (...)

AÉCIO NEVES: (1) minha querida conterrânea/ eu reconheço que você hoje expressa o sentimento de milhões de brasileiros/ que não aguentam mais abrir todo dia os jornais/ e ver qual é o caso novo de corrupçãol\. (2) e quando não há punição/ (3) a indignação é ainda maior \. (4) é o que nós estamos assistindo no Brasil de hojel\. (5) eu vejo a candidata Dilma apresentar aqui um conjunto de propostas \. (6) muitas delas estavam em tramitação no Congresso Nacional durante todos esses últimos anos $\backslash$. (7) não houve qualquer ação do PT ou do governo do PT/ (8) para que algumas dessas propostas pudessem avançar $\$. (...)

Nesse excerto, DR busca produzir uma resposta suficientemente adequada, concordando, inicialmente, com a avaliação feita pela eleitora acerca da brandura da lei contra corrupção (intervenção formada pelos atos 1-7) e subordinando, em seguida, essa intervenção à consequência que dela pode ser derivada: foi necessário propor outras cinco medidas de combate à impunidade (do ato $8 \mathrm{em}$ diante). Essas intervenções se articulam não por coordenação, mas por subordinação, como evidencia o conector por isso, que sinaliza que entre as informações que articula há uma relação de argumento e que a primeira intervenção é subordinada à segunda.

Já na réplica de $\mathrm{AN}$, o candidato, assim como a adversária, inicia sua intervenção expressando, em (1-4), sua simpatia em relação ao sentimento da eleitora de indignação contra a corrupção. Como a asserção inicial do candidato ecoa suas reiteradas acusações de corrupção, ao longo do debate, contra o governo da adversária, essa asserção e a conclusão que dela se pode derivar (o governo não combate a corrupção) funcionam como contra-argumentos para a acusação que o candidato faz na intervenção formada pelos atos (5-8) e com a qual busca desacreditar as medidas apontadas pela adversária. Essa interpretação se sustenta com a possibilidade de se inserir um conector contra-argumentativo (mas) no início dessa intervenção: "[mas] (5) eu vejo a candidata Dilma apresentar aqui um conjunto de propostas $\backslash .(\ldots)^{\prime \prime}$.

Assim como ocorre na resposta de DR, foram identificados conectores sinalizando a relação de subordinação textual/hierárquica entre as informações expressas em diferentes etapas de construção de respostas, réplicas e tréplicas dos candidatos. Além da expressão conectiva por isso [que], há ainda ocorrências dos conectores assim, portanto, mas.

\subsection{Ocorrências de segmentos de discurso representado diafônico e polifônico}

Como vimos, os candidatos buscam alcançar a completude de suas respostas, réplicas e tréplicas, ligando cada etapa de formulação dessas intervenções a informações da MD com origem na intervenção previamente produzida 
pelo adversário ou na pergunta de integrante da plateia. Esse modo de alcançar a completude monológica faz com que sejam frequentes, no debate estudado, ocorrências de segmentos de discurso representado diafônico ${ }^{11}$. Nesse debate, identificamos um total de 63 ocorrências de segmentos de discurso representado diafônico e todos efetivos, ou seja, todos representando um discurso supostamente dito. Desse total 32 foram produzidos por DR e 31, por AN.

No debate, todas as ocorrências de discursos diafônicos permitiram a cada candidato sinalizar a retomada do discurso do interlocutor, indicando em qual informação da MD sua intervenção se ancora. Nesse sentido, a diafonia exerce, no nível informacional, a função de indicar a continuidade entre a intervenção em que ela ocorre e dada informação da $M D$, o que contribui para tornar a intervenção mais clara ou mais conforme às exigências comunicativas da completude monológica. É o que se observa no excerto 6, que constitui parte do excerto $5^{12}$.

6) ADRIANA PEREIRA DOS SANTOS: (...) (4) a corrupção é uma doença contagiosa/ que tem sido uma pedra no calcanhar de todos os governos \(5) causando danos irreparáveis \\. (6) acredito que isso se dá/ porque a lei que pune os corruptos é muito branda \\. (...)

DILMA ROUSSEFF: (1) Adriana/ você tem toda a razão\. (2) a lei é branda \. (3) quando a lei é branda/ (4) você investiga/. (5) você identifica/. (6) e na hora de punir o criminoso/ (7) o corrupto se evadel\. (...)

A candidata inicia sua resposta, representando em seu discurso um segmento específico da pergunta da eleitora ((6) "a lei que pune os corruptos é muito branda"), com o fim de indicar que abordará ou tematizará a brandura da lei que pune corruptos.

Para além desse funcionamento geral dos segmentos de discurso diafônico, a diafonia exibe um funcionamento distinto nas trocas iniciadas por candidatos e nas trocas iniciadas por integrantes da plateia selecionados para fazer perguntas. Nas trocas iniciadas por candidatos, os segmentos de discurso diafônico são empregados por um candidato com o fim expressar discordância em relação ao que disse o adversário, desacreditando ou refutando sua fala. Por isso, são bastante agressivos para a face do adversário (ROULET, 1999). É o que se observa no excerto 7, que retoma em parte o excerto 2 e que corresponde a uma troca formada por resposta, réplica e tréplica.

7) AÉCIO NEVES: (...) (28) a senhora será a primeira presidente da república pós plano real/ que deixará o país com uma inflação maior do que aquela que recebeu \\

DILMA ROUSSEFF: (1) eu acho que o senhor está mal informado\. (2) porque quem deixou o país com uma inflação maior do que recebeu/ foi o governo tucano do Fernando Henrique $\$. ....)

AÉCIO NEVES: (...) (2) a senhora acaba de dizer que o governo do presidente Fernando Henrique deixou a inflação maior do que recebeu \. (3) em noventa e quatro candidata/ a inflação era de novecentos e dezesseis por cento ao ano \\. (4) o plano real que o seu governo/ que o seu partido votou contra/ permitiu que ela chegasse a sete e meio por cento\. e depois com a eleição do presidente Lula a doze e meio por cento \\ (...)

Nessa troca, a diafonia auxilia cada candidato a refutar informações expressas previamente pelo adversário, porque torna ainda mais evidente o alvo da refutação. Desse modo, ela o auxilia a construir uma intervenção que possa ser considerada adequada, por exemplo, pelo eleitor indeciso.

Já nas trocas iniciadas por eleitores, a diafonia tem por função permitir ao candidato expressar sua simpatia pelo eleitor, sua concordância em relação a observações feitas por ele, bem como seu interesse pela pergunta. Nesse sentido, por meio do segmento de discurso diafônico, o candidato busca construir uma intervenção que atenda às exigências comunicativa (continuidade informacional) e ritual (valorização das faces em jogo) da completude monológica. Assim, ao retomar um objeto de discurso ativado na pergunta do eleitor, o candidato costuma já tentar

11. A abordagem genebrina de análise do discurso, ao estudar os fenômenos relativos à polifonia, propõe três tipos de discursos representados. Um discurso representado pode ser autofônico (o locutor representa seu próprio discurso), diafônico (o locutor representa o discurso do interlocutor) ou polifônico (o locutor representa o discurso de terceiros) (ROULET; FILLIETTAZ; GROBET, 2001; CUNHA; BRAGA, 2018).

12. Neste item, os segmentos de discurso diafônico estão marcados em negrito. 
evidenciar sua sensibilidade em relação ao problema vivenciado por ele, como ocorre no excerto 8 , que se constitui de parte do excerto 3 .

8) LUIZ ALEXANDRE FILHO: (...) (6) qual será a sua política para quem mora de aluguel//. (7) pois está cada vez mais difícil e muito mais caro alugar uma casa \. (8) os preços estão muito acima da inflação\. (9) moro há 15 anos/ (10) e o meu aluguel triplicou nos últimos quatro anos $\backslash$

AÉCIO NEVES: (1) Luiz Alexandre/ esse é um drama que milhões de brasileiros vivem $\backslash$. (2) a dificuldade de pagar aluguel/ (3) e a dificuldade de ter a sua casa própria \. (...)

O candidato inicia sua resposta com um ato em que categoriza a dificuldade de pagar aluguel como "drama", termo não usado pelo eleitor, mas que permite ao candidato expressar uma sensibilidade em relação à experiência relatada por ele nos atos (9-10): ("(9) moro há 15 anos/ (10) e o meu aluguel triplicou nos últimos quatro anos\\"). No segmento de discurso diafônico produzido pelo candidato (atos 2-3), ele reelabora a proposição "está cada vez mais difícil e muito mais caro alugar uma casa" do eleitor em dois sintagmas nominais nucleados pelo item dificuldade, nominalização de item utilizado pelo próprio eleitor (difícil): "a dificuldade de pagar aluguel" e "a dificuldade de ter a sua casa própria". O uso da nominalização pelo candidato contribui para criar o efeito de que ele está atento aos problemas abordados pelo eleitor e os leva em consideração.

A simpatia ou o interesse pela pergunta do eleitor se manifesta ainda nas várias ocorrências de segmentos de discurso diafônico em que a fala do eleitor é apenas designada pelo item "pergunta", sempre acompanhado de um atributo elogioso ou da manifestação de contentamento, como exemplificam os excertos 9 e 10.

9) DILMA ROUSSEFF: (1) muito boa a sua pergunta \\; (1) Luiz Alexandre/ muito boa a pergunta \\; (1) Carla/ muito boa sua pergunta\\

10) AÉCIO NEVES: (1) Renata/ eu respondo com uma alegria enorme a sua pergunta\ com um cumprimento\\

Em todas essas ocorrências, o ato em que ocorre o segmento de discurso diafônico exerce uma função, sobretudo, ritual, no que se refere ao alcance da completude monológica, já que tem o papel de valorizar a face do eleitor. O excerto 10, por exemplo, permite ao candidato mais do que tecer um elogio, como faz DR no excerto 9, expressar qual será seu estado de espírito ("alegria enorme") durante a elaboração da resposta.

Nas trocas iniciadas por eleitores, há ainda segmentos em que cada candidato representa o discurso do adversário. Contudo, nessas trocas, quando um candidato representa o discurso do adversário, ele nunca o representa por meio de um segmento de discurso diafônico, mas sempre por meio de um segmento de discurso polifônico. Em outros termos, nas trocas iniciadas por eleitores, o candidato sempre identifica o eleitor como seu interlocutor e relega o adversário ao papel de um terceiro, como ocorre no excerto 11.

11) VERA LÚCIA AZEVEDO SIMÕES: (...) (11) qual a proposta para melhorar essa realidade/ (12) que tem prejudicado os jovens e destruído famílias//

DILMA ROUSSEFF: (...) (16) quando você vai num estado/ (17) eles [criminosos] fogem pra outro\\. (18) eles agem de forma coordenada \. (19) nós agimos de forma desarticulada e fragmentada \\. (...)

AÉCIO NEVES: (1) Vera Lúcia/ realmente o governo federal/ (2) como diz a candidata oficial/ (3) age de forma desarticulada nessa questão \. (4) e como confirma a candidata/ (5) não executa os fundos que são aprovados pelo Congresso Nacional/ (6) e não são tão expressivos mesmoll. (...)

Em sua réplica, AN escolhe a eleitora como sua interlocutora, como sinaliza o vocativo "Vera Lúcia", e se refere à adversária na $3^{a}$ pessoa: "a candidata oficial". Nessa réplica, toda a intervenção formada pelos atos (1-6) corresponde a um segmento em que o candidato representa este trecho do discurso da adversária: "(18) eles [criminosos] agem de forma coordenada \. (19) nós agimos de forma desarticulada e fragmentada \..". Como a instância cujo discurso ele representa é referida como um terceiro, o segmento de discurso representado é polifônico e não diafônico. Assim procedendo, o candidato busca, sobretudo, atacar a face da adversária, já que ele, além de a excluir do diálogo, 
sinaliza com os atos "como diz a candidata oficial/" e "e como confirma a candidata/" que utilizará um trecho de sua fala para desacreditar seu governo.

\section{CONSIDERAÇÕES FINAIS}

Neste trabalho, buscamos revelar que a reciprocidade parcial e controlada entre os adversários políticos que caracteriza o gênero debate eleitoral, tal como realizado no Brasil, impõe um modo de conduta específico para esses adversários alcançarem a completude de suas intervenções. Analisando à luz de contribuições teóricas e metodológicas da Escola de Genebra o último debate eleitoral da campanha presidencial de 2014, debate protagonizado por Dilma Rousseff (PT) e Aécio Neves (PSDB), verificamos que o fato de os candidatos não poderem decidir em que momento retroagir, intervindo quando a oportunidade surge, os leva a realizar manobras bastante complexas para a realização de uma intervenção que possa ser considerada suficientemente completa pelo interlocutor (adversário ou eleitor).

Os resultados alcançados evidenciam que as propriedades contextuais características de um dado gênero, tal como o debate, impõem restrições importantes sobre o modo de alcance da completude monológica pelos interlocutores. Com esses resultados, evidencia-se, assim, o interesse de estudos que investiguem de forma sistemática o modo de alcance da completude (dialógica e monológica) em diferentes contextos, bem como o papel das marcas linguísticas e textuais decorrentes das operações envolvidas no alcance da completude. O interesse desses estudos está exatamente em revelar que o alcance da completude monológica de uma intervenção (oral ou escrita) não é um processo descontextualizado e cuja responsabilidade recai apenas sobre seu produtor. Como revelado no presente estudo, trata-se, na verdade, de um processo altamente colaborativo e fortemente impactado pelas expectativas que subjazem à interação.

\section{REFERÊNCIAS}

BAKHTIN, M. (VOLOCHÍNOV). (1986[1929]). Marxismo e filosofia da linguagem. São Paulo: Hucitec.

BERRENDONER, A. (1983). "Connecteurs pragmatiques" et anaphore. Cabiers de linguistique française, v. 5, pp. $215-246$.

BROWN, P; LEVINSON, S. (1983). Politeness: some universals in language use. Cambridge: Cambridge University Press.

BURGER, M.; JACQUIN, J. (2015). La textualisation de l'oral: éléments pour une observation de la construction collaborative de la complétude. In: ADAM, J. M. (org.) Faire texte. Frontières textuelles et opérations de textualisation. Besançon: Presses universitaires de Franche-Comté, pp. 277-318.

CUNHA, G. X. (2017). O impacto da dimensão situacional do discurso sobre a articulação textual. Calidoscópio. v. 15, pp. 375 -387.

CUNHA, G. X. (2017a). O papel dos conectores na co-construção de imagens identitárias: o uso do mas em debates eleitorais. ALFA.v. 61, pp. 599-623.

CUNHA, G. X. (2017b). Conectores e processo de negociação: uma proposta discursiva para o estudo dos conectores. Fórum Linguístico. v. 14, pp. 1699-1716.

CUNHA, G. X. (2019). Estratégias de impolidez como propriedades definidoras de interações polêmicas. Delta: Documentação e Estudos em Linguística Teórica e Aplicada, v. 35, n. 2, pp. 1-28.

CUNHA, G. X. (2020). Elementos para uma abordagem interacionista das relações de discurso. Revista Linguística. v. 36, pp. 107-129.

CUNHA, G. X.; BRAGA, P. B. (2018). Definindo o comentário metadiscursivo em uma perspectiva interacionista da Análise do Discurso. SCRIPTA. v. 22, pp. 171-188.

CUNHA, G. X.; TOMAZI, M. M. (2019). O uso agressivo da linguagem em uma audiência: uma abordagem discursiva e interacionista para o estudo da im/polidez. Calidoscópio. v. 17, pp. 297-319.

DUCROT, O. (1987). O dizer e o dito. Campinas: Pontes. 
FILLIETTAZ, L. (2004). Négociation, textualisation et action: le concept de négociation dans le modèle genevois de l'organisation du discours. In: GROSJEAN, M.; MONDADA, L. (orgs.) La négociation au travail. Lyon: Presses universitaires de Lyon, pp. 69-96.

FILLIETTAZ, L. (2005). Négociation langagière et prise de décision dans le travail collectif. Négociations. v. 3, pp. 27-43.

FILLIETTAZ, L. (2006). La place du contexte dans une approche praxéologique du discours. Le cas de l'argumentation dans les interactions scolaires. Pratiques. v. 129-130, pp.71-88.

FILLIETTAZ, L. (2008). La co-construction des requêtes. Le cas du service à la clientèle dans les grandes surfaces. In: KERBRAT-ORECCHIONI, C.; TRAVERSO, V. (orgs.) Les interactions en site commercial: invariants et variations. Lyon: Ens Éditions, pp. 77-103.

FILLIETTAZ, L. (2014). L'interaction langagière: un object et une méthode d'analyse en formation des adultes. In: FRIEDRICH, J.; CASTRO, J. C. P. (orgs.) Recherches en formation des adultes: un dialogue entre concepts et réalité. Dijon: Raisons et Passions, pp. 127-162.

FILLIETTAZ, L.; ROULET, E. (2002). The Geneva Model of discourse analysis: an interactionist and modular approach to discourse organization. Discourse Studies. v. 4, n. 3, pp. 369-392.

GOFFMAN, E. (1967[1955]). On face-work: an analysis of ritual elements in social interaction. In: E. GOFFMAN. (org.) Interaction ritual: essays on face-to-face bebavior. New York, Pantheon Books, pp. 5-45.

GOFFMAN, E. (1973). La mise em scène de la vie quotidienne: les relations em public. v. 2. Paris: Les Éditions de Minuit.

GOFFMAN, E. (1981). Forms of talk. Philadelphia: University of Pennsylvania Press.

GRICE, H. P. (1975). Logic and conversation. In: COLE, P.; MORGAN, J. L. (orgs.) Sintax and semantics: speech acts. New York: Academic Press, pp. 41-58.

GUIMARÃEES, E. (1987). Texto e argumentação: um estudo de conjunções do português. São Paulo: Pontes.

JACQUIN, J. (2014). Débattre: l'argumentation et l'identité ao coeur d'une pratique verbale. Bruxelles: De Boeck Supérieur.

KERBRAT-ORECCHIONI, C. (2017). Les débats de l'entre-deux-tours des élections présidentielles françaises: constantes et évolutions d'un genre. Paris : L'Harmattan.

MARINHO, J. H. C. (2007). A determinação da unidade textual mínima. In : Marinho, J. H. C. ; Pires, M. S. O. ; Villela, A. M. N. (orgs.), Análise do discurso : ensaios sobre a complexidade discursiva. Belo Horizonte : CEFET-MG, pp. 39-50.

MOESCHLER, J. (1982). Dire et contredire: pragmatique de la négation et acte de réfutation dans la conversation. Berne: Peter Lang.

MOESCHLER, J. (1985). Argumentation et conversation: éléments pour une analyse pragmatique du discours. Paris: Hatier-Credif.

ROSSARI, C. (1996). Identification d'unités discursives: les actes et les connecteurs. Cabiers de linguistique française. v. 18, n. 1, pp. $157-177$.

ROULET, E. (1986). Complétude interactive et mouvements discursifs. Cabiers de linguistique francaise. v. 7, pp. $189-206$.

ROULET, E. (1987). Complétude interactive et connecteurs reformulatifs. Cabiers de linguistique francaise. v. 8, pp. 111-140.

ROULET, E. (1988). Variations sur la structure de l'échange langagier dans différentes situations d'interaction. Cabiers de linguistique française. v. 9, n. 1, pp. 27-37.

ROULET, E. (1992). On the structure of conversation as negociation. In: PARRET, H.; VERSCHUEREN, J. (orgs.) (On) Searle on conversation. Amsterdam: John Benjamins, pp. 91-99. 
ROULET, E. (1999). La description de l'organisation du discours. Paris: Didier.

ROULET, E. (2000). Enoncé, tour de parole et projection discursive. In: BERTHOUD A.C.; MONDADA, L. (orgs.) Modèles du discours en confrontation. Berne: Lang, pp. 5-22.

ROULET, E. (2004). Les relations de discours rhétoriques et praxéologiques dans la description des propriétés des constituants parenthétiques. Travaux de linguistique. v. 49, pp. 09-17.

ROULET, E. et al. (1985). L'articulation du discours en français contemporain. Berne: Lang.

ROULET, E.; FILLIETTAZ, L.; GROBET, A. (2001). Un modèle et un instrument d'analyse de l'organisation du discours. Berne: Lang.

SACKS, H.; SCHEGLOFF, E. A.; JEFFERSON, G. (1974). A simplest systematics for the organization of turn taking in conversation. Language. v. 50, pp. 696-735.

SCHEGLOFF, E. A. (2007). Sequence organization in interaction: a primer in Conversation Analysis I. Cambridge: Cambridge University Press.

Recebido: 3/10/2019

Aceito: $14 / 9 / 2020$

Publicado: 3/3/2021 